\title{
MAGNETIC RESONANCE IMAGING IN EVALUATION OF NON-TRAUMATIC AND NON-NEOPLASTIC CASES OF CERVICAL MYELOPATHY- A STUDY
}

\author{
Pooja Shah"1, Bhaskar Bhattacharyya², Tapan Dhibar ${ }^{3}$ \\ 1 Postgraduate Trainee, Department of Radiodiagnosis, IPGME \& R, Kolkata, West Bengal, India. \\ ${ }^{2}$ Associate Professor, Department of Radiodiagnosis, R. G. Kar Medical College, Kolkata, West Bengal, India. \\ 3 Professor, Department of Radiodiagnosis, Bangur Institute of Neurology, Kolkata, West Bengal, India.
}

\begin{tabular}{l}
\hline ABSTRACT \\
Cervical myelopathy is a common cause of major neurological disability. The purpose of our study was to evaluate the magnetic \\
resonance imaging (MRI) features and identification of the possible causes of cervical myelopathy in patients after ruling out \\
traumatic and neoplastic lesions.
\end{tabular}

\section{METHODS}

Patients of either sex, above the age of 12 years who were clinically diagnosed as nontraumatic cervical myelopathy were included in this study conducted in a tertiary centre of West Bengal over a period of 18 months. Later, we also excluded patients having neoplastic lesions detected by MRI. Following clinical examinations, selected patients underwent MRI of cervical spine in a 3 Tesla MR scanner to determine the aetiology of cervical myelopathy and to assess the morphology, location and extent of the causative lesion. Standard MRI sequences were used in different planes. Post contrast study was performed only in selected cases. This was an institution based descriptive study.

\section{RESULTS}

Forty-three patients of 14 to 80 years of age with a mean age of 48.5 years had nontraumatic and nonneoplastic causes contributing to cervical myelopathy. Nearly two-thirds of these patients were males and rest were females. Of the various nontraumatic and nonneoplastic causes, cervical spondylosis was by far the most common aetiology of cervical myelopathy, seen in nearly $58 \%$ of such patients.

\section{CONCLUSIONS}

We concluded that MRI was useful in lesion characterisation and depicting various causes of cervical myelopathy, thereby playing a very important role in management of these patients.

\section{KEY WORDS}

Cervical Myelopathy, Magnetic Resonance Imaging

HOW TO CITE THIS ARTICLE: Shah P, Bhattacharyya B, Dhibar T. Magnetic resonance imaging in evaluation of non-traumatic and non-neoplastic cases of cervical myelopathy- a study. J. Evolution Med. Dent. Sci. 2019;8(26):2041-2044, DOI: $10.14260 /$ jemds $/ 2019 / 450$

\section{BACKGROUND}

Myelopathy is defined as a disease or damage to spinal cord resulting in neurological deficit or dysfunction.(1) Cervical myelopathy is a common cause of significant neurological disability and its manifestations range from decreased hand dexterity, imbalance and incontinence and severe paralysis of all four limbs. Hence it is important to confirm the diagnosis of cervical myelopathy in a clinically suspected case and to determine its cause as it dictates the patient's management. Cervical spondylotic myelopathy (CSM) results from degenerative arthritis of cervical spine giving rise to posterior spondylotic ridges or osteophytes, disc herniation, facet joint arthropathy and ligamentum flavum hypertrophy/ buckling causing cervical cord compression and myelopathic changes.

'Financial or Other Competing Interest': None.

Submission 13-03-2019, Peer Review 16-06-2019,

Acceptance 21-06-2019, Published 01-07-2019.

Corresponding Author:

Dr. Bhaskar Bhattacharyya,

HA-150, Sector-3, Salt Lake City,

Kolkata-700097,

West Bengal, India.

E-mail: bhas_kar1974@yahoo.co.in

DOI: $10.14260 /$ jemds $/ 2019 / 450$

\section{(c) (i) $\$$}

Congenital atlanto- axial instability can cause compression on the cervical cord and myelopathy. The atlanto dental interval of more than $5 \mathrm{~mm}$ in flexion indicates instability. $(2,3)$ Ossified posterior longitudinal ligament (OPLL) represents ossification along posterior aspect of vertebral bodies either as continuous or discrete forms causing narrowing of cervical spinal canal and compression of the cervical cord. Hirayama disease typically occurs in young males of 15 to25 years.(4) On flexion-extension MRI, there is forward migration of the posterior thecal wall compressing the cord causing its flattening and signal changes. The other important causes of CSM are rheumatoid arthritis and tuberculosis of spine. Rheumatoid Arthritis causes erosion of dens, atlanto-axial subluxation, inflammatory thickening of synovium called pannus, and these can compress the cord. Tuberculous spondylodiscitis has the propensity to involve the thoracic spine, though cervical spine is no exception.

Cervical myelopathic changes can also result from some important non compressive causes like ischaemia, demyelination and radiation injury. Inflammatory demyelinating diseases of the cord can be of following types acute disseminated encephalomyelitis (ADEM), multiple sclerosis (MS), neuro myelitis optica (NMO) and transverse myelitis (TM). Many patients who are initially diagnosed with ADEM or TM may have recurrent diseases and later turn out 
to be having MS.(5) Spinal vascular malformation can cause cord ischemia or haemorrhage and cord may later atrophy. These vascular malformations consist of spinal arteriovenous malformation/fistula (AVM/AVF), spinal haemangiomas, cavernomas and aneurysms. The diagnosis rests on MRI and magnetic resonance angiography (MRA) and is confirmed by digital subtraction angiography (DSA).(6) Syrinx, which may result from various causes (inflammation, injury, Chiari malformations etc.), can cause cervical myelopathy. Radiation induced myelopathy can occur when cervical cord gets included in the radiation field for treatment of head and neck malignancies.

\section{Aims and Objectives}

1. Identifying the various imaging features in patients with clinical diagnosis of cervical myelopathy (Non traumatic and non-neoplastic) in terms of MRI parameters detected on various sequences of MRI i.e, axialT2, sagT2, sagT1, axialT1, coronal STIR, sag GRE, MERGE and contrast when required.

2. Determining the aetiology of CM on MRI.

3. Determining the type, exact location and extent of the detected lesions.

\section{METHODS}

Patients of either sex, above the age of 12 years who were clinically diagnosed as non-traumatic cervical myelopathy had been recruited in this study which was conducted in a tertiary centre of West Bengal over a period of 18 months. We also excluded patients with cervical myelopathy due to neoplastic lesions detected by MRI. After obtaining history proper clinical examination of the patients was done. The selected patients underwent MRI of cervical spine to determine the aetiology of cervical myelopathy and to assess the morphology, location/level and extent of the causative lesion. We used a 3 Tesla MR scanner for imaging. Standard MRI sequences like T2, T1, STIR and GRE were used in imaging of the cervical spine in different planes. Imaging following administration of gadolinium contrast was performed in selected cases. This was an Institution based comparative cross-sectional study.

\section{Study Design}

It is a descriptive study.

\section{Ethics}

The study had been conducted in accordance with the ethical standards of the responsible committee on human experimentation (institutional).

\section{Statistics}

For data analysis appropriate statistical methods were used.

\section{RESULTS}

The distribution of the age of the patients is shown in Table 1. It shows the range of age from 14 years to 80 years with a mean age of 48.5 years. Table 2 shows that nearly two-thirds $(67.4 \%)$ of the total 43 patients were males and the remaining were females. Table 3 summarises the distribution of aetiological diagnosis of cervical myelopathy made by MRI. It shows that CSM was by far the most common cause of cervical myelopathy and was present in approximately $58 \%$ of patients.

\begin{tabular}{|c|c|c|c|c|c|c|}
\hline & Number & Mean & S.D. & Minimum & Maximum & Median \\
\hline Age & 43 & 48.5116 & 18.3178 & 14.0000 & 80.0000 & 47.0000 \\
\hline \multicolumn{7}{c|}{ Table 1. Distribution of Mean Age } \\
\hline
\end{tabular}

\begin{tabular}{|c|c|c|}
\hline Sex & Frequency & Percent \\
\hline Female & 14 & $32.6 \%$ \\
\hline Male & 29 & $67.4 \%$ \\
\hline Total & 43 & $100.0 \%$ \\
\hline \multicolumn{2}{|c|}{ Table 2. Distribution of Sex } \\
\hline
\end{tabular}

\begin{tabular}{|c|c|c|}
\hline Diagnosis & Frequency & Percent \\
\hline AAD & 1 & $2.3 \%$ \\
\hline ADEM & 1 & $2.3 \%$ \\
\hline AVM & 1 & $2.3 \%$ \\
\hline CSM & 25 & $58.1 \%$ \\
\hline HRM & 3 & $7.0 \%$ \\
\hline MS & 2 & $4.7 \%$ \\
\hline NMO & 1 & $2.3 \%$ \\
\hline OPLL & 2 & $4.7 \%$ \\
\hline RAM & 1 & $2.3 \%$ \\
\hline RDM & 1 & $2.3 \%$ \\
\hline SYNX & 3 & $7.0 \%$ \\
\hline TBM & 2 & $4.7 \%$ \\
\hline Total & 43 & $\mathbf{1 0 0 . 0 \%}$ \\
\hline Table 3. Distribution of Diagnosis by MRI \\
\hline \multicolumn{2}{|c|}{} \\
\hline
\end{tabular}
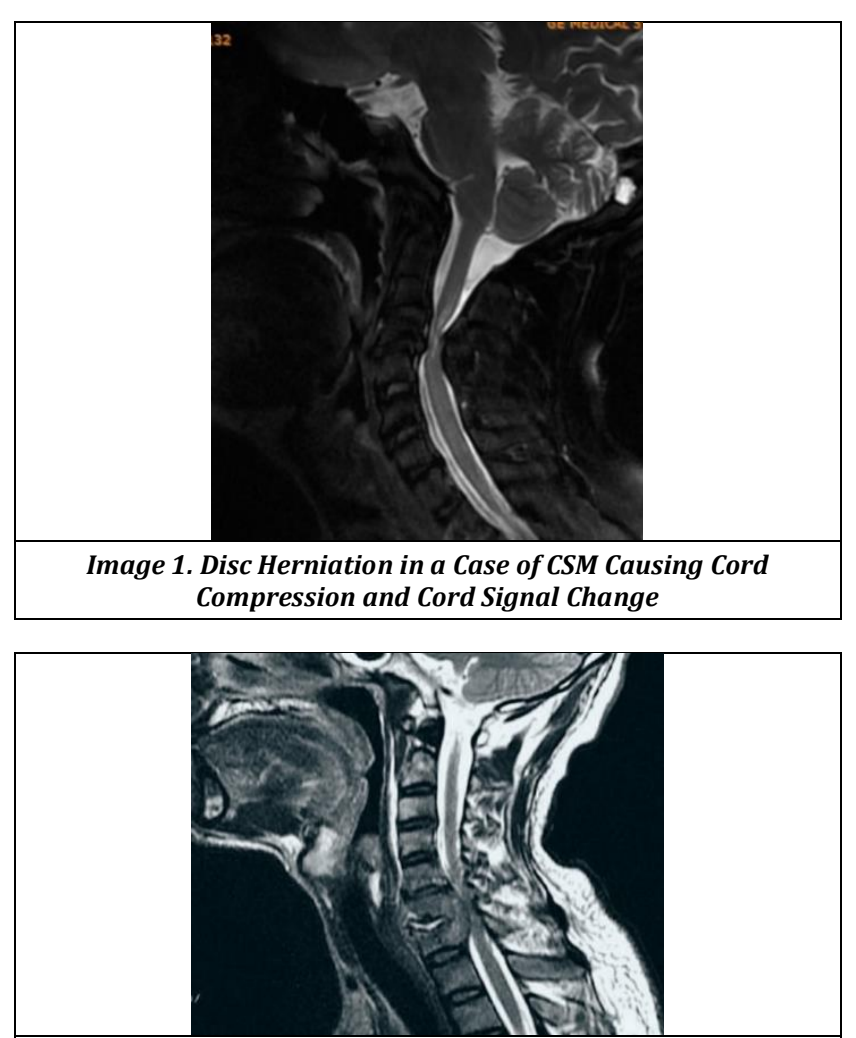

Image 2. Perivertebral Soft Tissue in a Case of Tuberculous Spondylitis Causing Cord Compression and Signal Change
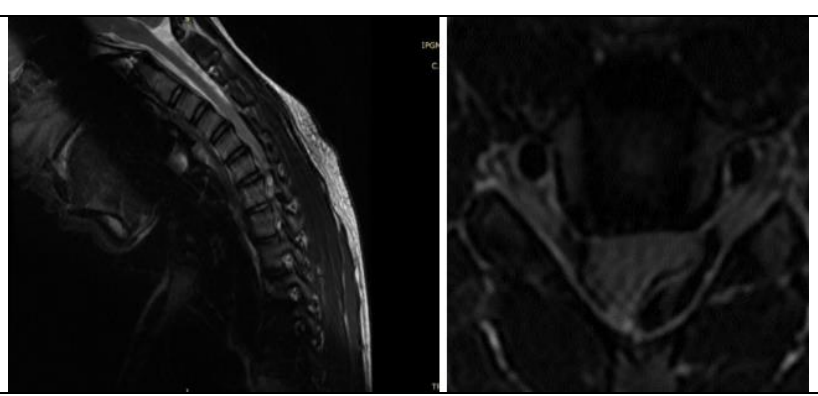

Image 3 \& 4. Anteriorly Shifted Posterior Dura Mater, Crescent Shaped Posterior Epidural Space with Prominent Flow Void 


\section{DISCUSSION}

The present study involving 43 patients having non traumatic, non-neoplastic cervical myelopathy suggested various causes of myelopathic changes in MRI. The mean age of our patients was 48.5 years with an approximate male to female ratio of $2: 1$. Out of these 43 patients we had twenty five $(58.1 \%)$ cases of CSM, seen more in males (64\%) and majority in patients above 50 years of age with a mean age of 58.3 years. Similar findings were noted in a study conducted by Lindsay Tetreault et al(7) and other earlier studies $(8,9)$. The abnormalities demonstrated by MRI were anterior subarachnoid space obliteration, cord compression and abnormal signal intensities in the cord (Hyperintensity in $\mathrm{T} 2$, hypo-/iso-intensity in T1 weighted sequences) suggestive of myelopathy, which were uniformly present in all cases of CSM. Among these 25 cases of CSM we found disc herniation in 23 cases, posterior osteophytes in 9 cases, facet joint arthropathy in 5 cases, coexistent OPLL in 1 case, ligamentum flavum hypertrophy in 6 cases and spondylolisthesis in 2 cases.

In our study, we found two (4.7\%) cases of isolated OPLL, both in male patients with a mean age of 58 years. The study done by Wang M.Y. et al in 2001 proposed the incidence of OPLL to be $2.4 \%$ in the Asian population and $0.16 \%$ in the non-Asian population (10). It is twice as common in men as in women, and symptomatic OPLL usually presents in the 5 th to 6 th decade of life, which goes with our finding. OPLL induced changes in MRI in both cases were anterior subarachnoid space obliteration, cord compression and spinal cord signal alterations suggestive of myelopathy.

We had three $(7 \%)$ patients of syringomyelia of which two were male and one female with the mean age of presentation of 33 years. Hassan Ahmad Hassan Al-Shatoury reported that the prevalence of the disease in population was about 8.4 per 100,000 and occurred more frequently in men than in women.(11) The disease usually appears in the third or fourth decade of life, with a mean age of onset of 30 years. There was no evidence of spinal cord compression in our patients, however intramedullary lesions having C.S.F. like signal intensity favouring syrinx were noted. These finding were in accordance to a study done by B.C. Lee et al.(12)

In our study, two (4.7\%) patients had tuberculous spondylodiscitis associated compressive cervical myelopathy; both of them are male with mean age of presentation being 37.5 years. MRI showed vertebral destruction, intervertebral disc involvement with pre and paravertebral lesions in these cases. Epidural lesion compressing the cord and with resultant cord oedema was seen in both cases which correlated with the study by Roos DEA et al(13) Involvement of multiple vertebral bodies similar to the findings in earlier studies including that by Prateek S. Gehlot et al was noted.(14) Contrast study was done for better characterisation of the lesions which were seen to subside in follow up MRI after course of anti-tubercular therapy.

We had four $(9.3 \%)$ cases of demyelinating myelopathy including 1 case of ADEM, 2 cases of MS and 1 case of NMO. A provisional diagnosis of ADEM was made in a 19 year old male with recent history of viral infection on the basis of MRI findings of hyperintensity in the cord in $\mathrm{T} 2$ sequence extending over multiple vertebral segments with mild cord expansion which were similar to findings in earlier studies including that by Singh et al in 2002.(15) Coexisting white matter T2 hyperintense lesions in brain was also in favour of ADEM. The spinal cord lesion suggestive of NMO in a 42-yearold male patient was longitudinally extensive, centrally located extending over three vertebral segments (C4 to C7). MRI of brain and orbits done in this patient complaining of visual symptoms revealed bilateral optic neuritis. The spinal cord lesion in our patient of NMO was similar to that described by Winger chuck et al in 2006.(16) MRI of cervical spine in two proven cases of MS showed peripherally located altered signal intensity involving less than two vertebral segments and occupying less than two-thirds of the cross section of the cord, compatible with MS as described by Tartaglino et al.(17)

We made a diagnosis of Hirayama disease in three patients (7\%); all were male patients with median age of presentation at 25.6 years, which was in accordance with the studies done by Kevin Talbot and Shweta Thakur et al.(18,19) Precontrast MRI in neutral position showed abnormal cervical curvature (in 2 cases), localised lower cervical cord atrophy with asymmetric cord flattening and intramedullary hyperintensity in lower cervical cord (in 3 cases). On dynamic post contrast study (in flexion), we found interiorly shifted dura mater (in 2 cases), prominent epidural flow void (in 2 cases), enhancing epidural mass in lower cervical region (in 3 cases) and congested posterior internal vertebral venous plexus (in 1 case). The findings were diagnostic of Hirayama disease and were observed in earlier studies including that by Chen C. J. et al.(20)

We diagnosed radiation induced myelopathy in a 62-yearold male patient who had a history of radiation therapy for laryngeal cancer. MRI revealed T2 hyperintensity with swelling of cervical cord along with diffusely increased signal intensity of the vertebrae due to fatty replacement of marrow secondary to radiation seen in T1 weighted sequence. Similar MRI findings of radiation myelopathy were described by Hung T.P. et al and Wang et al.(21,22) One 27-year-old female patient had spinal vascular malformation. MRI in this patient revealed long segment intramedullary hyperintensity with surrounding flow voids in T2 weighted images, which corresponded to findings of an earlier study by Minami S. et al.(23) We had one 14-year male patient with atlanto-axial dislocation. MRI of cervical spine in this patient showed increased atlanto-dental distance with compression and T2 hyperintensity of upper cervical cord which were also observed by Wang et al.(24) In this study a 42-year female patient with history of long-standing rheumatoid arthritis was diagnosed with compressive myelopathy secondary to complications of rheumatoid arthritis. Erosion of odontoid and pannus formation compressing the upper cervical cord causing myelopathic changes were noted in MRI, similar to findings described by Bouchard-Chabot A. et al.(25)

By using MRI, in non-traumatic and non-neoplastic cases of cervical myelopathy, we determined the underlying causes and provided detailed morphological assessment of these compressive and non-compressive lesions contributing to myelopathic changes. Aetiological diagnosis of cervical myelopathy with characterisation of the underlying pathology can be done well by MRI, which has established itself as the imaging modality of choice for assessment of intervertebral discs, spinal cord, subarachnoid space, ligaments and other soft tissues in relation to spine. From our study we concluded that MRI was very useful in 
differentiating between various compressive and noncompressive causes of cervical myelopathy.

\author{
Abbreviations \\ AAD- Atlanto Axial Dislocation. \\ CSM- Cervical Spondylotic Myelopathy. \\ SYNX- Syrinx. \\ HRM- Hirayama disease. \\ TBM- Tuberculous Myelopathy. \\ RDM- Radiation Myelopathy. \\ RAM- Rheumatoid Arthritis associated Myelopathy. \\ MS- Multiple Sclerosis. \\ ADEM- Acute Disseminated Encephalomyelitis. \\ NMO- Neuromyelitis Optica. \\ OPLL- Ossified Posterior Longitudinal Ligament. \\ AVM- Arterio Venous Malformation.
}

\section{CONCLUSIONS}

MRI was useful in lesion characterisation and depiction of various causes of cervical myelopathy, thereby playing a very important role in management of these patients.

\section{REFERENCES}

[1] Payne EE, Spillane J. The cervical spine: an anatomicopathological study of 70 specimens (using a special technique) with particular reference to the problem of cervical spondylosis. Brain 1957;80(4):571-96.

[2] Swischuk LE. Emergency imaging of the acutely ill or injured child. The spine and the spinal cord. $4^{\text {th }}$ edn. Philadelphia, Pa: Lippincott Williams \& Wilkins 2000: p. 532-87.

[3] Bonadio WA. Cervical spine trauma in children: Part II. Mechanisms and manifestations of injury, therapeutic considerations. Am J Emerg Med 1993;11(3):256-78.

[4] Hassan KM, Sahani H, Jha A. Clinical and radiological profile of Hirayama disease: a flexion myelopathy due to tight cervical dural canal amenable to collar therapy. Ann Indian Acad Neurol 2012;15(2):106-12.

[5] Transverse Myelitis Consortium Working Group. Proposed diagnostic criteria and nosology of acute transverse myelitis. Neurology 2002;59(4):499-505.

[6] Lin N, Smith ER, Scott RM, et al. Safety of neuroangiography and embolization in children: complication analysis of 697 consecutive procedures in 394 patients. J Neurosurg Pediatr 2015;16(4):4328.

[7] Tetreault L, Goldstein CL, Arnold P, et al. Degenerative cervical myelopathy: a spectrum of related disorders affecting the aging spine. Neurosurgery 2015;77(Suppl 4):S51-S67.

[8] Wu JC, Ko CC, Yen YS, et al. Epidemiology of cervical spondylotic myelopathy and its risk of causing spinal cord injury: a national cohort study: a national cohort study. Neurosurg Focus 2013;35(1):E10.
[9] Northover JR, Wild JB, Braybrooke J, et al. The epidemiology of cervical spondylotic myelopathy. Skeletal Radiol 2012;41(12):1543-6.

[10] Wang MY, Thambuswamy M. Ossification of the posterior longitudinal ligament in non-Asians: demographic, clinical, and radiographic findings in 43 patients. Neurosurg Focus 2011;30(3):E4.

[11] Al-Shatoury HAH. Syringomyelia. Medscape. Jul 08, 2016.

http://emedicine.medscape.com/article/1151685overview

[12] Lee BC, Zimmerman RD, Manning JJ, et al. MR imaging of syringomyelia and hydromyelia. Am J Roentgenol 1985;144(6):1149-56.

[13] De Roos A, Van Persijin Van Meertan EL, Bloem JL, et al. MRI of tubercular spondylitis. Am J Roentgenol 1986;147(1):79-82.

[14] Gehlot PS, Chaturvedi S, Kashyap R, et al. Pott's spine: retrospective analysis of MRI scan of 70 cases. J Clindiagn Res 2012;6(9):1534-8.

[15] Singh S, Prabhakar S, Korah IP, et al. Acute disseminated encephalomyelitis and multiple sclerosis: magnetic resonance imaging differentiation. Australas Radiology 2000;44(4):404-11.

[16] Wingerchuk DM, Lennon VA, Pittock SJ, et al. Revised diagnostic criteria for neuromyelitis optica. Neurology 2006;66(10):1485-9.

[17] Tartaglino LM, Friedman DP, Flanders AE, et al. Multiple sclerosis in the spinal cord: MR appearance and correlation with clinical parameters. Radiology 1995;195(3):725-32.

[18] Talbot K. Monomelic amyotrophy or Hirayama disease. Practical Neurology 2004;4(6):362-5.

[19] Thakur S, Sood RG, Jhobta A, et al. Hirayama disease in unilateral and bilateral forms-3 case reports. The Egyptian Journal of Radiology and Nuclear Medicine 2013;44(2):291-5.

[20] Chen CJ, Chen CM, Wu CL, et al. Hirayama disease: MR diagnosis. Am J Neuroradiol 1998;19(2):365-8.

[21] Hung TP. Myelopathy following radiotherapy of nasopharyngeal carcinoma. Proc Aust Assoc Neurol 1968;5(2):421-8.

[22] Wang PY, Shen WC, Jan JS. Serial MRI changes in radiation myelopathy. Neuroradiology 1995;37(5):374-7.

[23] Minami S, Sagoh T, Nishimura K, et al. Spinal arteriovenous malformation: MR imaging. Radiology 1988;169(1):109-15.

[24] Wang S, Wang C, Yan M, et al. Novel surgical classification and treatment strategy for atlantoaxial dislocations. Spine (Phila $\mathrm{Pa}$ 1976) 2013;38(21):E1348-56.

[25] Bouchaud-Chabot A, Lioté F. Cervical spine involvement in rheumatoid arthritis: a review. Joint Bone Spine 2002;69(2):141-54. 